\title{
Reflexões sobre o Parlamento do MERCOSUL
}

JAmiLe Lourdes FerReIRA TAJRA

Resumo: O Parlamento do MERCOSUL foi criado para ser o órgão de representação dos povos e fomentar a cidadania sul-americana. Após apresentar a trajetória do MERCOSUL, este artigo aborda as características e as atividades do Parlasul entre 2007 e 2014, delineando, ao final, alguns entraves ao seu pleno funcionamento.

Palavras-Chave: Integração Sul-americana; Parlamento do MERCOSUL; Cidadania sul-americana.

$\overline{\text { Jamile Lourdes Ferreira TaJRA }}$

Doutoranda em Ciência Política pela Universidade Federal do Rio Grande do Sul (UFRGS). Integra o Grupo de Pesquisa Processos Participativos na Gestão Pública (UFRGS) e o Observatório das Nacionalidades (UECE). jamiletajra@gmail.com.

\section{Reflections on the MERCOSUL Parliament}

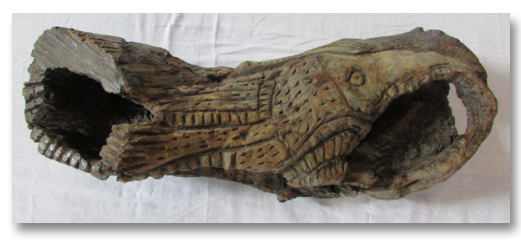

Abstract: The Mercosur Parliament was created to be the place that represents the people and to foment South American citizenship. After presenting Mercosur trajectory, this paper addresses the Parlasur's characteristics and activities between 2007 and 2014 . Finally, it outlines some obstacles to completing its operation.

Keywords: South American integration; Mercosur Parliament; SouthAmerican Citizenship.

RECEBIDO EM: 02/11/2015

AProvado EM: 11/01/2016 


\section{INTRODUÇÃO}

O Parlamento do MERCOSUL (Parlasul), sediado em Montevidéu, Uruguai, foi instituído em 2005 e substituiu a Comissão Parlamentar Conjunta (CPC), antigo órgão de representação legislativa dos Estados partes do MERCOSUL. Idealizado para cumprir as funções de representação dos povos e viabilizar a harmonização das legislações nacionais de modo a que estas recebam com maior facilidade a normativa criada pelos acordos firmados no âmbito do bloco, o Parlasul trouxe a questão do envolvimento do cidadão para centro do debate acerca da integração regional, apresentando-se como elemento central no fomento a uma "cidadania do MERCOSUL" (FIER, 2008).

Seguindo a tendência de outros processos de integração regional, em que a instituição de órgãos parlamentares transnacionais, via de regra, apareceu para responder às demandas pela participação popular em tais processos e mesmo para promover a legitimidade destes perante os indivíduos em última instância envolvidos, os cidadãos (DRUMMOND, 2005), o órgão assumiria o desafio de sanar o déficit democrático, fortalecer a institucionalidade e, com isso, trazer maior legitimidade e transparência ao bloco, até então carente de um instrumento de absorção das demandas cidadãs. Neste sentido, o Parlasul propiciaria aos seus cidadãos o conhecimento acerca da produção dos órgãos decisórios e, mais que isso, dar-lhes-ia a possibilidade de participação, ainda que indireta, na produção normativa do MERCOSUL.

O texto aqui apresentado traz uma discussão desenvolvida no âmbito da pesquisa de mestrado que deu origem a dissertação intitulada: "Integração sul-americana: uma incursão ao conceito de cidadania no âmbito do Parlamento do MERCOSUL" (TAJRA, 2014a), defendida na Universidade Estadual do Ceará, UECE, Brasil, em 2014, acerca do conteúdo da cidadania do MERCOSUL proposta pelo Parlasul.

Além desta introdução, o texto apresenta duas seções e uma conclusão. A primeira seção expõe brevemente, e de maneira geral, a trajetória do MERCOSUL, perpassando seu caráter inicial, marcadamente comercial, até o momento em que a integração política, social e cultural passou a ter destaque entre os acordos 
firmados pelos governantes do bloco, contexto que possibilitou a instituição do Parlasul. Em seguida aborda-se as principais características institucionais do órgão, além de suas atividades entre os anos 2007 e 2010 e 2011 a 2014, ${ }^{1}$ definidos pelo cronograma oficial como primeira e segunda etapa de institucionalização do órgão, numa tentativa de verificar o cumprimento às atribuições e os principais temas trabalhados por este. Por fim, traça-se um panorama global dos instrumentos dedicados ao fomento à cidadania e em que medida o Parlasul abriu o espaço para a cidadania no bloco. A título de conclusão, apresento brevemente os achados da pesquisa acerca da cidadania do MERCOSUL deflagrada pelo Parlasul.

\section{MERCOSUL: ENTRE AS RELAÇÕES COMERCIAIS E A INTEGRAÇÃO CIDADÃ}

Ainda que desde a sua fundação se previsse a integração em múltiplos níveis (econômico, político, social e cultural como os principais deles), nos primeiros anos após a assinatura do Tratado de Assunção, em março de 1991, mesmo que o MERCOSUL tenha se mantido como ator coadjuvante nos planos de inserção internacional de seus sócios, o que se percebeu foi um claro avanço no campo comercial, sobretudo entre Argentina e Brasil, cuja balança comercial cresceu significativamente com relação ao período anterior a assinatura de Assunção.

No ano 2000, por ocasião da XVIII reunião do Conselho do Mercado Comum (CMC), no esforço conjunto de aprofundar e fortalecer o bloco, a iniciativa conhecida como relanzamiento do MERCOSUL ${ }^{2}$ trazia consigo a possibilidade de um alargamento institucional que em muito favoreceu o surgimento tanto de acordos temáticos quanto de novos órgãos e secretarias, além de reuniões especializadas e de Ministros sociais e de desenvolvimento,

\footnotetext{
1 Por se tratar de informações relevantes, embora para caráter de análise de dados acerca do conteúdo da atividade parlamentar do órgão, o recorte temporal do artigo se encerre em 2014, a fim de oferecer informações mais atuais, foram incluídos alguns dados de 2015.

2 Decisões CMC n. 22 a 32/2000.
} 
todos trazendo à cena a importância de fortalecer os direitos cidadãos no âmbito do bloco e, com isso, fomentar uma "cidadania sul-americana" ou uma "cidadadania do MERCOSUL". Na mesma reunião foi ainda, aprovada a Carta de Buenos Aires sobre o Compromisso Social no MERCOSUL, Bolívia e Chile.

No Brasil, as diretrizes da política externa do governo Fernando Henrique Cardoso (FHC) (1995-2002), embora estabelecendo múltiplos eixos para a atuação internacional do país, não deixou de apresentar importantes bases, não apenas quanto às inclinações políticas, mas também quanto ao conteúdo institucional da integração sul-americana. Através de iniciativa pessoal do Presidente FHC, e tomando como base seu projeto de desenvolvimento para o país (Plano Avança Brasil), seriam realizadas as duas primeiras Reuniões de Presidentes da América do Sul. Essa iniciativa do governo de FHC, ainda que não tenha se dado no âmbito exclusivo do MERCOSUL, já que reuniu os presidentes de todos os países da região, simbolizou um ponto de transição entre a velha e a nova fase das relações diplomáticas do Brasil com seus vizinhos (SANTOS, 2005, 2014).

Assim, a partir das Cúpulas de Brasília (2000) e Guayaquil (2002), ambas com ativo envolvimento do Brasil, "a definição de "América do Sul" na retórica diplomática brasileira adquiriu, finalmente, contornos definidos - englobando as doze nações (e só estas), que foram convidadas para participar dos dois encontros" (SANTOS, 2005, p. 201).

Também a partir de 2002, a emergência de líderes de orientação centro-esquerdista nos quatro países então integrantes do MERCOSUL inauguraria um momento favorável ao desenvolvimento de outras instâncias da integração sul-americana. Sua estrutura institucional passou a acolher a possibilidade de absorção de organismos para a conformação dos parâmetros políticos e sociais, até então ausentes nas iniciativas no âmbito do bloco (BETHONICO, 2007; PIETRAFESA, 2009).

Em 2003, o presidente Luis Inácio Lula da Silva (2003-2010) estabeleceria, desde os primeiros momentos de seu governo, o aprofundamento das relações com os países sul-americanos como prioridade da política externa brasileira (SANTOS, 2005, 2014). Já 
em seu discurso de posse, o novo presidente do Brasil ratificava a condução que seu governo pretendia dar a integração regional. Dizia Lula da Silva (2003, grifos nosso):

A grande prioridade da política externa durante o meu Governo será a construção de uma América do Sul politicamente estável, próspera e unida, com base em ideais democráticos e de justiça social. Para isso é essencial uma ação decidida de revitalização do Mercosul, enfraquecido pelas crises de cada um de seus membros e por visões muitas vezes estreitas e egoístas do significado da integração. $O$ Mercosul, assim como a integração da América do Sul em seu conjunto, é sobretudo um projeto político. Mas esse projeto repousa em alicerces econômico-comerciais que precisam ser urgentemente reparados e reforçados. Cuidaremos também das dimensões social, cultural e científico-tecnológica do processo de integração. Estimularemos empreendimentos conjuntos e fomentaremos um vivo intercâmbio intelectual e artístico entre os países sul-americanos. Apoiaremos os arranjos institucionais necessários, para que possa florescer uma verdadeira identidade do Mercosul e da América do Sul.

Dali por diante, o ponto de partida para uma nova inserção do Brasil no cenário internacional seria a América do Sul - consolidada a partir da reconstrução do MERCOSUL e de outras iniciativas regionais no esforço de integração (SANTOS, 2005, 2014).

Nesse contexto, a criação da Comunidade Sul-Americana de Nações (CASA), em dezembro de 2004, demonstrava igualmente que, "mais do que a "circunstância do Brasil", a América do Sul [tornava-se] a referência para a inserção brasileira no mundo do século que se abre" (SANTOS, 2005, p. 203). A partir dali, fugindo à trajetória traçada nos primeiros anos após sua instituição, marcados por um caráter essencialmente comercial, o arcabouço institucional do MERCOSUL passou a absorver a possibilidade de criação e instituição de órgãos que promovessem a integração política e social, sem abandonar a econômico- comercial já - embora com inúmeras dificuldades - encaminhadas. ${ }^{3}$

3 O primeiro órgão social do bloco, o Foro Consultivo Econômico e Social (FCES), composto por representantes dos setores sindical e empresarial, lembrese, foi instituído pelo Protocolo de Ouro Preto, em 1994, mas a abertura efetiva do arcabouço institucional do MERCOSUL aos órgãos de cunho essencialmente social somente pôde ser observado com a mudança de governantes nos quatro países, o que possibilitou uma reorientação dos rumos da integração regional. 
Neste contexto destaca-se nos últimos anos, a criação, em 2004, do Fundo de Convergência Estrutural do MERCOSUL (FOCEM), que consta de uma poupança regional para o financiamento de projetos de infraestrutura na região, no intuito de minimizar as assimetrias existentes entre os países em prol de um desenvolvimento regional equilibrado; do Foro Consultivo de Municípios, Estados Federados, Províncias e Departamentos do MERCOSUL (FCCR), instituído no mesmo ano com o objetivo de aproximar as instâncias municipais do processo de integração regional; e, no ano de 2009, do Instituto Social do MERCOSUL (ISM), no intuito de avançar com o objetivo geral de promover o desenvolvimento da dimensão social no âmbito do bloco (TAJRA; MARTINS, 2014).

Durante a Cúpula Presidencial de Costa do Sauipe, Bahia, Brasil, ocorrida em dezembro de 2008, foi criada ainda a Comissão de Coordenação de Ministros de Assuntos Sociais do MERCOSUL (CCMAS), definida a estrutura do ISM e estabelecidos os eixos e diretrizes para a elaboração de um Plano Estratégico de Ação Social do MERCOSUL (PEAS). O PEAS, por sua vez, elaborado no âmbito da Reunião de Ministros e Diretores de Desenvolvimento Social e do ISM, veio a ser aprovado pelo CMC em junho de 2011, por ocasião da Cúpula de Assunção. Em seus 26 artigos, apresenta os eixos, diretrizes e objetivos prioritários para a ação estratégica do bloco nos diversos setores da integração social e delineia os principais desafios à sua efetivação (MERCOSUL, 2011).

A integração política vinha à cena, pois, como uma dentre as inúmeras oportunidades na agenda da integração (PIETRAFESA, 2009). Naquela altura, "as eleições de Lula, no Brasil, em outubro de 2002, e de Néstor Kirchner para Presidente da Argentina, em abril de 2003, dariam origem a uma conjunção de fatores favoráveis à 'parlamentarização' do MERCOSUL" (DRUMMOND, 2005, p. 317). Foi então que, em reunião entre os presidentes do bloco em Buenos Aires, em outubro de 2003, se apresentou formalmente a intenção política do estabelecimento de um órgão de representação dos povos no âmbito da estrutura institucional do MERCOSUL.

Articulou-se a partir dali uma série de ações no âmbito dos Estados partes para fundar o Parlamento regional em um futuro próximo. Por indicação do poder executivo brasileiro foi designado 
um grupo de consultores legislativos da Câmara e do Senado para dar suporte à elaboração do Protocolo Constitutivo do Parlamento do MERCOSUL (PCPM) (MERCOSUL, 2008c). Em 2005, o Parlasul foi criado em substituição a Comissão Parlamentar Conjunta (CPC), ficando regido pelo disposto no referido Protocolo.

Além do PCPM, o Parlasul tem sua normativa orientada pelo disposto no Regimento Interno do Parlamento do MERCOSUL (PCPM) (MERCOSUL, 2007), na Declaração Presidencial sobre o Compromisso Democrático no MERCOSUL, de 1996 e no Protocolo de Ushuaia sobre o Compromisso Democrático no MERCOSUL, a República da Bolívia e a República do Chile, assinado em 1998.

\section{O PARLASUL E O FOMENTO À CIDADANIA DO MERCOSUL}

A Comissão Parlamentar Conjunta do MERCOSUL (CPC) lembre-se, fora instituída já pelo Tratado de Assunção (MERCOSUL, 2008a), em 1991. Este, em suas Disposições Gerais (artigo 24), assegurava o estabelecimento de um órgão legislativo que funcionasse como instrumento de discussão democrática e de representação dos Estados partes do MERCOSUL. O Protocolo de Ouro Preto (MERCOSUL, 2008b), em 1994, por sua vez, estabeleceu que o órgão legislativo do MERCOSUL arquitetar-se-ia como foro de representação dos Estados envolvidos, a quem caberia à responsabilidade de harmonizar as legislações internas de seus membros, a fim de que estas absorvessem prontamente as determinações estabelecidas pelos órgãos decisórios do bloco.

Em termos regimentais, a CPC funcionava como plataforma de representação parlamentar dos Estados partes do MERCOSUL, e, por isso, cada delegação nacional era composta por igual número de parlamentares, escolhidos por meio de procedimentos internos dentre os integrantes das esferas legislativas nacionais - (no Brasil, Câmara dos Deputados e Senado Federal) - e tinha como principais funções: ${ }^{4}$

4 Protocolo de Ouro Preto (1994) - da Comissão Parlamentar Conjunta, Seção IV, artigos 22 ao 27. 
1. estreitar os laços entre as estruturas jurídico-legais nacionais dos respectivos Estados parte à do MERCOSUL, preparando-as para a plena entrada em vigor das normas firmadas pelos demais órgãos do bloco;

2. auxiliar o CMC fornecendo relatórios, pareceres e recomendações a este enviadas por intermédio do GMC acerca do andamento da integração nas esferas política, econômica, social e cultural e;

3. promover as bases institucionais para que se vislumbrasse futuramente a participação direta, por meio do sufrágio universal, dos cidadãos dos Estados partes no processo da integração regional.

Para a execução dessas funções, a CPC iniciou suas atividades em 1995 com 90 parlamentares, sendo 18 para cada Estado parte. No Brasil, a representação parlamentar no MERCOSUL se deu pela divisão equânime do número de lugares entre a Câmara dos Deputados e o Senado Federal.

A decisão específica de instituir um Parlamento no MERCOSUL, substituindo a CPC, por sua vez, foi uma iniciativa dos líderes executivos dos dois maiores países do bloco. Assim, os presidentes da Argentina e do Brasil, com vistas a conferir maior legitimidade ao processo de integração por meio do reconhecimento político da sociedade, apresentaram, na ocasião de um encontro entre os presidentes do bloco, em Brasília, em junho de 2003, por meio de um comunicado à imprensa, a proposta de criação de um Parlamento regional. O órgão, no entanto, só viria a iniciar suas atividades e a compor a base institucional do bloco a partir de janeiro de 2007.

No momento imediatamente posterior à entrada em vigor do PCPM, porém, o Parlasul funcionou nos moldes da CPC para aperfeiçoar a proposta da representação cidadã em termos técnicos, de modo a dar suporte às posteriores decisões políticas dos órgãos decisórios do bloco, apresentando ainda a divisão paritária dos lugares entre os Estados partes como parâmetro definidor da distribuição de lugares também na primeira fase de institucionalização do Parlasul (DRI, 2009; DRUMMOND, 2005; PIETRAFESA, 2009; TAJRA, 2014a, b). 
O novo órgão, de acordo com o PCPM, foi instituído com os seguintes propósitos:

1. representar aos povos do MERCOSUL, respeitando sua pluralidade ideológica e política;

2. assumir a promoção e defesa permanente da democracia, da liberdade e da paz;

3. promover o desenvolvimento sustentável da região com justiça social e respeito à diversidade cultural de suas populações;

4. garantir a participação dos atores da sociedade civil no processo de integração;

5. estimular a formação de uma consciência coletiva de valores cidadãos e comunitários para a integração;

6. contribuir para consolidar a integração latino-americana mediante o aprofundamento e ampliação do MERCOSUL e;

7. promover a solidariedade e a cooperação regional e internacional (MERCOSUL, 2008c).

No entanto, assim como a CPC, o Parlasul, mesmo compondo oficialmente a estrutura orgânica do MERCOSUL, não está subordinado à sua hierarquia institucional. Assim, tem autonomia, mas não possui faculdades decisórias próprias, funcionando, por ora, como órgão de consultoria e assessoria para os demais órgãos do bloco, principalmente o CMC e o Grupo Mercado Comum (GMC).

A mais evidente diferença do Parlamento em relação à CPC, é a de que enquanto esta representava os Estados partes do MERCOSUL, e por isso mesmo as cadeiras no órgão eram distribuídas de forma paritária entre eles, o Parlasul viria a ser o órgão de representação do cidadão, motivo pelo qual, juntamente com os mecanismos necessários para a realização das eleições diretas, a questão da adequação das bancadas ao tamanho das populações se fizesse tão necessária quanto urgente, incluindo também a questão da representação no processo de institucionalização do órgão. 
De acordo com sua hierarquia institucional, o Parlasul é composto por um presidente e, um vice-presidente por Estado parte, eleitos por maioria qualificada ${ }^{5}$ pelo período de seis meses, alternando-se ciclicamente e por ordem alfabética os Estados partes na ocupação da presidência. O órgão conta também com uma mesa diretora responsável por conduzir os trabalhos legislativos e dos serviços administrativos, também dotada de um presidente, e um vice-presidente para cada Estado parte, porém eleitos por dois anos com direito a uma reeleição, além de um secretário parlamentar e um secretário administrativo, eleitos no início de cada período parlamentar ${ }^{6}$ por designação da própria mesa (MERCOSUL, 2007).

O RIPM prevê ainda, a constituição de comissões parlamentares permanentes, que contam com um presidente e um vice-presidente eleitos pelo período de dois anos, além de comissões temporárias e especiais que, criadas para analisar determinado assunto, extinguem-se ao término do respectivo período parlamentar.

As delegações externas, por sua vez, dão conta de representar o Parlasul junto aos demais órgãos parlamentares internacionais, Estados e organismos multilaterais. Ademais, o Parlamento conta com a possibilidade de criação de grupos políticos que, respeitando a normativa específica para seu estabelecimento, ${ }^{7}$ agregam os parlamentares segundo suas afinidades e plataformas de atuação políticas.

No período compreendido entre 1994, ano da assinatura do Protocolo de Ouro Preto (MERCOSUL, 2008b), e dezembro de 2006, quando o PCPM entrou internacionalmente em vigor e a CPC foi oficialmente substituída pelo Parlasul, por conta principalmente de suas funções limitadas, a trajetória da CPC foi marcada,

5 Voto afirmativo da maioria absoluta da representação parlamentar de cada Estado parte.

6 Contabiliza-se como um período parlamentar o intervalo temporal de seis meses.

7 Para que se possa estabelecer um grupo político deve-se obedecer ao mínimo de $10 \%$ dos parlamentares, se estes forem representantes de um único Estado parte ou; 5 parlamentares, se forem representantes de mais de um Estado parte, além de que cada Parlamentar só pode tomar parte em um grupo político (RIPM, 2007, Capítulo 3, Grupos Políticos). 
sobretudo, por atividades de consultoria aos órgãos decisórios do bloco - além do CMC, ao GMC e à Comissão de Comércio do MERCOSUL (CCM) -; e por um déficit na representação cidadã, já que esta não absorvia as demandas sociais dos cidadãos de cada Estado parte, os quais eram dotados de igual representação no foro regional (TAJRA, 2014b).

O princípio da equidade, observado na CPC e no primeiro momento após a instituição do órgão, não contemplava o desigual contingente populacional dos países envolvidos. Como justificar dotar Paraguai, Uruguai e Venezuela da mesma representatividade que cabe ao Brasil, ou mesmo à Argentina, dado que estes detêm um contingente populacional consideravelmente maior? A função representativa do Parlasul, dessa forma, desde o primeiro momento, foi perpassada por contendas acerca da efetividade e mesmo da validade do órgão parlamentar regional.

O Brasil, sob vários aspectos (território, população, PIB) sócio majoritário do MERCOSUL, em 2010, estimava uma população de 190.7 milhões de habitantes (INSTITUTO BRASILEIRO DE GEOGRAFIA E ESTATÍSTICA, 2010). A Argentina, nesse mesmo ano, possuía aproximadamente 40.091 milhões (INSTITUTO NACIONAL DE ESTADÍSTICA Y CENSOS, 2010); a Venezuela, então em processo de adesão e participando na condição de membro associado, mas já com representação no Parlasul, projetava para 2010 uma população de 28,8 milhões (INSTITUTO NACIONAL DE ESTADÍSTICA, 2000); o Uruguai, contava com cerca de 3,3 milhões (INSTITUTO NACIONAL DE ESTADÍSTICA, 2005) de habitantes no mesmo ano e o Paraguai, segundo dados de 2009, possuía 6,3 milhões. ${ }^{9}$ Nestes termos, para ilustrar a questão da representação com dois casos extremos, na primeira etapa, quando cada país contava com igual número de lugares no Parlasul, ao tempo em que um parlamentar uruguaio representava cerca de

8 População estimada com base no censo 2001, que contava 24,765 milhões de habitantes (INSTITUTO NACIONAL DE ESTADÍSTICA, 2000).

9 O Paraguai realizou novo censo em 2012, porém os dados aqui se baseiam no Anuário Estadístico del Paraguay (2009). 
183 mil, um parlamentar brasileiro estaria representando cerca de 10,5 milhões de pessoas. ${ }^{10}$

A "equidade" de representação entre os Estados partes, dessa forma, logo se tornaria insuficiente. Manter o princípio da equidade e munir todos os Estados partes com a mesma representação seria absorver uma situação de déficit na representação dos mais populosos em detrimento da super-representação daqueles com menor contingente populacional. A adaptação das regras de acesso ao Parlasul trataria, pois, de incluir regras específicas que determinassem nos processos nacionais de escolha dos parlamentares o ajuste do número de cadeiras dispostas para cada um dos Estados dentro dos períodos estabelecidos nas "Disposições transitórias" do PCPM. Este, então, propôs etapas de transição gradual até que se desse por completo a implementação do órgão, tornando-o de fato representativo das populações envolvidas. Assim, definiu como "primeira etapa da transição", o período compreendido entre 31 de dezembro de 2006 e 31 de dezembro de 2010; e como "segunda etapa de transição", o período entre $1^{\circ}$ de janeiro de 2011 e 31 de dezembro de 2014.

Na primeira etapa, os lugares no Parlasul seriam ocupados pelos parlamentares eleitos nas respectivas esferas nacionais; na segunda, os parlamentares deveriam ser escolhidos por meio de eleições diretas, ficando cada um dos Estados responsável por decidir os critérios de sua representação e pela realização do processo eleitoral em seu território. O cronograma previa também que a partir desta segunda fase todos os Estados partes fixassem uma data comum para a realização das eleições diretas, que se denominaria "Dia do MERCOSUL Cidadão" (MERCOSUL, 2008c).

Seguindo, o cronograma previsto, passada a primeira etapa, em que cada país contava com 18 lugares no Parlasul, a partir de $1^{\circ}$ de janeiro de 2011, ao Brasil, caberia ocupar 37 lugares; à Argentina, dos 18 na primeira fase, caberia 26 na segunda. Uruguai e Paraguai permaneceriam com o mesmo número de 18 lugares cada um nas

10 Cálculo simples da população total dividida por 18, número de cadeiras reservada a cada Estado parte na primeira etapa de institucionalização do Parlasul. 
duas fases de institucionalização do órgão. A Venezuela, então em processo de adesão, na categoria de observador, contou com 18 lugares na primeira etapa, passando a 27 na segunda.

Pelo critério da proporcionalidade atenuada (ACORDO define..., 2015), passadas as duas etapas de institucionalização, a partir de $1^{\circ}$ de janeiro de 2015, o Brasil contaria com 75 postos; a Argentina com 43, a Venezuela com 31, o Paraguai e o Uruguai permanecendo com a mesma quantidade das fases anteriores. Assim, o Parlasul evoluiria de 80 parlamentares na primeira etapa; para 126 na segunda e 185 a partir de 2015.

O cronograma eleitoral estabelecido pelo PCPM, juntamente com as fases de transição, no entanto, não foi cumprido por quatro dos cinco países, já que somente o Paraguai elegeu seus representantes de forma direta no prazo previsto, em 2008. A Argentina, somente realizou suas eleições diretas para o Parlasul mais recentemente, em outubro de 2015, enquanto Brasil, Uruguai e Venezuela permanecem em dívida quanto ao cumprimento do acordo.

Diante dos atrasos no cronograma previsto, a Decisão do CMC $n^{\circ}$ 18/11, que aprovou a Recomendação do Parlasul no 16/10, autorizou que este continuasse funcionando até $2014 \mathrm{com}$ representantes designados pelos Parlamentos nacionais. Como, ainda assim, até 2014, quatro dos cinco Estados partes não haviam realizado suas eleições diretas, a última diretriz do órgão no tocante ao estabelecimento de prazos foi mais generosa, determinando 31 de dezembro de 2020 como data limite para que os cinco Estados partes (talvez seis, se até lá o bloco tiver concluído o processo de adesão da Bolívia) realizem as eleições diretas de seus Parlamentares do MERCOSUL.

Quanto às suas atividades, o Parlasul manifesta-se por meio de anteprojetos e projetos de norma, pareceres, declarações, relatórios, disposições e recomendações aos Estados partes, aos demais órgãos do bloco e a Estados e organismos extra-bloco. No tocante à sua organização interna, esta foi planejada de forma que os grupos políticos se articulem e permitam a reunião dos parlamentares segundo alianças de interesse, para além das bandeiras partidárias. Foi acordado que a manutenção financeira do órgão 
se daria por meio de financiamento público, com a contribuição de cada Estado parte definida em função de seu Produto Interno Bruto (PIB) e dos orçamentos nacionais, à exceção da "primeira etapa de transição", cujo orçamento ficou constituído pela contribuição em partes iguais para cada país.

Em dezembro de 2008, com a missão de elaborar um projeto que viabilizasse a interação entre o CMC e o Parlasul, por decisão do primeiro, reunido em Salvador, Bahia, foi criado o Grupo de Alto Nível sobre Relação Institucional entre o CMC e o Parlasul (GANREL), a ser composto por representantes dos Estados Partes designados pelas Coordenações Nacionais do GMC, estabelecido pelo Decreto $\mathrm{n}^{\circ}$ 47, 15 de dezembro de 2008, do CMC.

A ação no intuito de colaborar para o desenvolvimento de uma cidadania sul-americana, entretanto, somente apareceria de maneira expressa e articulada nos planos de ação dos documentos oficiais emanados do bloco dois anos depois, quando a decisão do CMC 64/2010 acordava um Plano de Ação para a criação do Estatuto da cidadania do MERCOSUL. O Caput do documento afirma a necessidade de

consolidar um conjunto de direitos fundamentais e benefícios em favor dos nacionais dos Estados Partes do MERCOSUL e estabelecer um Plano de Ação para a conformação progressiva de um Estatuto da Cidadania do MERCOSUL, com vistas a sua plena implementação no trigésimo aniversário da assinatura do Tratado de Assunção (MERCOSUL, 2010).

O documento estabeleceu eixos centrais, tais quais: a) a implementação de uma política de livre circulação de pessoas na região; b) a igualdade de direitos e liberdades civis, sociais, culturais e econômicas para os nacionais dos Estados Partes do MERCOSUL e; c) a igualdade de condições para acesso ao trabalho, saúde e educação. ${ }^{11}$

O Plano de ação estabeleceu ainda, onze temas de inflexão, tais como: circulação de pessoas, fronteiras, identificação, documentação e cooperação consular, trabalho e emprego, previdência social, educação, transporte, comunicações, defesa do consumidor

11 Art. $2^{\circ}$ da Dec. CMC No 64/10 (MERCOSUL, 2010). 
e direitos políticos. Destaque-se este último, o qual prevê a avaliação das condições para o avanço progressivo no estabelecimento de direitos políticos, "de acordo com as legislações nacionais que regulamentem seu exercício, em favor dos cidadãos de um dos Estados partes do MERCOSUL que residam em outro Estado parte de que não sejam nacionais" (MERCOSUL, 2010). ${ }^{12}$

O documento estabeleceu, por fim, o prazo de 10 anos para a progressiva implementação do Plano de ação, de modo que, tendo em vista o exercício da "cidadania do MERCOSUL", por ocasião do $30^{\circ}$ aniversário do MERCOSUL (a rigor, 26 de março de 2021), esteja integralmente incorporado.

Contudo, contrariando o previsto pelos cronogramas e acordos firmados para sua implementação, o Parlasul por duas ocasiões encontrou-se desativado devido, entre outros motivos, ao fato de que três dos cinco países com direito a representação no órgão, incluindo o Brasil, à revelia do que previa seu Protocolo Constitutivo (PCPM), não terem ainda realizado eleições diretas para Parlamentares do MERCOSUL.

Transcendendo o previsto nos documentos oficiais, a curta trajetória até aqui traçada pelo Parlasul, demonstra, assim, que a integração dos povos da região não há de se concretizar sem que haja uma plataforma de discussões em que o conflito - inerente aos processos sociais de modo geral - venha à cena, contendo e, por vezes, atrasando o processo da integração cidadã.

Entre janeiro de 2011 e dezembro de 2012, o Parlasul ficou paralisado devido ao não envio do Brasil e, posteriormente, da Argentina, de seus representantes. Em maio de 2015, os 122 parlamentares do órgão novamente suspenderam suas atividades, desta vez por falta de verba para as despesas administrativas. A falta de um orçamento próprio fez com que o déficit acumulado chegasse a US\$5,1 milhões, dos quais o Brasil é o maior devedor (PARLASUL suspende..., (2015).

O Parlasul é, ainda, alvo de críticas que denunciam as controvérsias de um órgão legislativo sem o poder de legislar, visto que do ponto de vista jurídico, não se pode pensar ainda em uma

12 Art. $3^{\circ}$ da Dec. CMC No 64/10 (MERCOSUL, 2010). 
instância legislativa plena acima dos Estados nacionais entre os países do MERCOSUL. A falta de competência decisória do órgão faz com que, no limite de suas capacidades e atribuições institucionais, este funcione como órgão de consultoria aos órgãos decisórios do MERCOSUL, o que relegaria o Parlasul a uma posição acessória ou meramente retórica no funcionamento do bloco.

Neste quesito, porém, chama-se atenção para o que se considera a competência mais importante do Parlasul, a competência consultiva disposta no artigo $4^{\circ}$, inciso 12 do PCPM, que prevê que, durante a negociação de uma norma pelo Executivo do bloco, este consulte o Parlamento como forma de obter a chancela das populações representadas pelos parlamentares democraticamente eleitos (TAJRA, 2014a). Este mecanismo de controle, entretanto, ainda não foi implementado e, por conseguinte, o horizonte institucional do Parlasul permanece limitado.

\section{CONCLUSÃO: UM BALANÇO DAS ATIVIDADES E DOS ENTRAVES AO PARLASUL}

A ideia de constituir um Parlamento no MERCOSUL, uma iniciativa do Brasil em parceria com a Argentina, com a posterior adesão dos demais sócios, trouxe para o bloco a possibilidade, ainda que indireta, de envolver o cidadão no processo decisório no âmbito da integração sul-americana. No entanto, a possibilidade de exercício e o alcance dessa cidadania são postos em xeque diante, sobretudo, da fragilidade institucional e da ausência de competências legislativas do Parlasul.

Como respostas às perguntas levantadas pela pesquisa sobre a contribuição do órgão para o acesso universal aos direitos políticos e sociais e para a luta pelo reconhecimento da igualdade de direitos nos países do MERCOSUL, a absorção da participação popular do órgão parlamentar da integração sul-americana e, a contribuição deste para a articulação dos movimentos sociais organizados da região pode-se inferir que o Parlasul inaugurou a possibilidade da sociedade civil apresentar propostas que, uma vez aceitas, poderão ser levadas aos órgãos decisórios do bloco 
sob a forma de anteprojetos ou projetos de norma ou ainda de recomendações (TAJRA, 2014a).

Porém, mesmo como plataforma de criação e discussão de projetos a serem levados ao CMC e demais órgãos executivos, $\mathrm{O}$ Parlasul apresenta uma possibilidade, por ora, pouco perceptível, visto que no limite de sua competência consultiva, suas propostas de normas não possuem caráter vinculativo, ou seja, seu cumprimento não se traduz em obrigação para os órgãos executivos do bloco. Além disso, para o cidadão, esse acesso se dá mediante a aproximação e negociação com os grupos políticos dentro do órgão, que, por sua vez, encontram-se ainda muito atrelados às bandeiras partidárias e ao repertório das demandas políticas nacionais.

No que concerne à mobilização cidadã, percebe-se a ênfase na atuação dos grupos profissionais no tocante à sugestão de uma legislação educacional e trabalhista mais flexível entre os países membros. No entanto, o fato de suas sessões parlamentares e reuniões ordinárias ocorrerem sempre em sua sede, em Montevidéu, também se apresenta como fator isolador do órgão, que acaba por ter seu alcance limitado às regiões de fronteira, $\mathrm{O}$ que se reflete em sua pauta de discussões. Nesse sentido, as regiões fronteiriças são bastante mais sensíveis ao processo de integração do que aquelas afastadas das fronteiras entre os países do bloco.

No tocante às atividades do órgão, quando se lança uma análise sobre seu conteúdo, o que se percebe é um claro destaque dado aos temas concernentes à melhoria da interação entre as cadeias produtivas e da estrutura viária para a livre circulação dos fatores de produção (pessoas e mercadorias) entre os países. A integração dos recursos energéticos também consta como alvo constante da atenção dos parlamentares, que procuram destacar a importância estratégica do setor para os países envolvidos (MERCOSUL, 2007-2014).

Diante das hipóteses levantadas e confirmadas pela pesquisa, pode-se inferir que a "cidadania do MERCOSUL" ou a "cidadania sul-americana", levada a cabo pelo Parlasul, deflagrada tanto nos depoimentos colhidos quanto nos documentos oficiais (especificamente, anteprojetos e projetos de norma, pareceres e declarações) 
emitidos em nome do órgão, demonstra de antemão, um caráter fortemente mercadológico.

Os direitos civis, como os de livre circulação e livre exercício profissional, assim, tem um claro destaque nas ações do Parlasul. Os direitos sociais, a seu turno, como, por exemplo, o acesso aos sistemas de saúde, educação e inclusão social, espera ainda, um tratamento mais direto por parte das ações do órgão. Além disso, ao observar o conteúdo da atividade do órgão, percebe-se que a dileção pela implementação de projetos na região da tríplice fronteira revela que o viés comercial da integração sul-americana ainda prevalece sobre os campos político, social e cultural.

Concluo, no entanto, que o Parlamento do MERCOSUL, apesar dos problemas que enfrenta, sobretudo o dos atrasos na sua institucionalização e seus problemas orçamentários, carrega a missão importante institucional de aproximar o cidadão do processo de integração em curso. É por meio dele que, como uma via de mão dupla, os representantes democraticamente eleitos proporão projetos e áreas prioritárias para a integração dos mais variádos setores aos órgãos decisórios do bloco e que, se implementado o artigo $4^{\circ}$, inciso 12 do PCPM, os parlamentares poderão conferir uma maior legitimidade às decisões finais desses mesmos órgãos, visto que, como um órgao de consulta, as instâncias executivas devem submeter todos os acordos assinados pelos governantes dos Estados partes ao crivo das populaçoes afetadas, representadas pelos democraticamente eleitos parlamentares do MERCOSUL. Nesse sentido, dar prosseguimento ao cronograma previsto pelo PCPM torna-se urgente para a própria sobrevivência do órgão, implementar suas competências, por sua vez, é imprescindível para o desenvolvimento da cidadania do MERCOSUL.

\section{REFERÊNCIAS}

ACORDO define proporcionalidade no Parlasul. Agência Câmara. Disponível em: <http://www2.camara.leg.br/camaranoticias/ noticias/132028.html $>$. Acesso em: 2 out. 2015.

ANUÁRIO ESTADÍSTICO DEL PARAGUAY. Asuncion, 2009. 
Disponível em: <http://www.dgeec.gov.py/Publicaciones/ Biblioteca/Anuario2009/cap\% 2002.pdf>. Acesso em: 6 jun. 2011.

BETHONICO, C. C. de O. Os Direitos Humanos no MERCOSUL. Revista de Direitos Fundamentais e Democracia, Curitiba, v. 2, n. 2, jul./dez. 2007. Disponível em: <http://revistaeletronicardfd. unibrasil.com.br/index.php/rdfd/article/view/142>. Acesso: 10 out. 2015.

DRI, C. At what point does a legislature become institucionalized? The MERCOSUR Parliament's path. Brasilian Political Science Review, v. 3, n. 2, p. 60-97, 20097. Availabre from: <http://www. plataformademocratica.org/Publicacoes/17828_Cached.pdf $>$. Aceso: 15 out. 2015.

DRUMMOND, M. C. A democracia desconstruída. O déficit democrático nas reações internacionais e os parlamentos da integração. 2005. Tese (Doutorado) - Instituto de Ciências Humanas, Departamento de História, Universidade de Brasília, Brasília, 2005.

FIER, F. [Deputado Federal Dr. Rosinha]. Parlamento do MERCOSUL: identidade comum e cidadania. Brasília: Parlamento do MERCOSUL, 2008. Disponível em: <http://www. senado.gov.br/evmMERCOSUL//publico/setores/000/33/ noticias/2008/8/358/ Artigo\%20Rosinha\%20-\%200\%20 Parlamento\%20do\%20MERCOSUL\%20e\%20cidadania pdf $>$. Acesso em: 8 out. 2014.

INSTITUTO BRASILEIRO DE GEOGRAFIA E ESTATÍSTICA. Censo 2010. Disponível em: <http://www.ibge.gov.br/home/ estatistica/populacao/censo2010/default_sinopse.shtm>. Acesso em: 6 jun. 2011.

INSTITUTO NACIONAL DE ESTADÍSTICA. Proyeciones de Población - "Población total, según entidad federal al 30 de Junio, 2000-2015". Disponível em: <http://www.ine.gov.ve/>. Acesso em: 06/jun./2011.

INSTITUTO NACIONAL DE ESTADÍSTICA. Estímativas y proyecciónes de la población de Uruguay - 1996-2025. Revisão 2005. Disponível em: <http://www.ine.gub.uy/>. Acesso em: 6 jun. 2011. 
INSTITUTO NACIONAL DE ESTADÍSTICAS Y CENSOS. Censo 2010. Disponível em: <http://www.censo2010.indec.gov.ar>. Acesso em: 6 jun. 2011.

LULA DA SILVA, Luis Inácio. Discurso de posse do presidente da República. Brasília: Secretaria de Imprensa e Divulgação da Presidência da República, 2003.

MERCOSUL. Base de dados documentais do Parlamento do MERCOSUL. 2007-2014. Disponível em: <http://www. parlamentodelmercosur.org:8090/archivos/>. Acesso em: 22 out. 2015.

Plano Estratégico de Ação Social do MERCOSUL, PEAS. Instituto Social do MERCOSUL (ISM), 2011. Disponível em: $<$ http://ismercosur.org/doc/PEAS-Portugues-web.pdf>. Acesso em: 3 mar. 2015.

Estatuto da cidadania do MERCOSUL - plano de ação. Cúpula Social do MERCOSUL, 2010. Disponível em: <http://www. mercosur.int/innovaportal/file/2810/1/DEC Estatuto_da_Cidadania.pdf>. Acesso em: 24 maio 2013.

. Tratado de Assunção. Assunção, Paraguai. In: MAZZUOLI, V. de O. (Org.). Coletânea de Direito Internacional. 6. ed. São Paulo: Revista dos Tribunais, 2008a.

- Protocolo Adicional ao Tratado de Assunção sobre a estrutura institucional do MERCOSUL - Protocolo de Ouro Preto. In: MAZZUOLI, V. de O. (Org.). Coletânea de Direito Internacional. 6. ed. São Paulo: Revista dos Tribunais, 2008b.

Protocolo Constitutivo do Parlamento do MERCOSUL. Montevidéu. In: MAZZUOLI, V. de O. (Org.). Coletânea de Direito Internacional. 6. ed. São Paulo: Revista dos Tribunais, 2008c.

Regimento Interno do Parlamento do MERCOSUL. Tradução da Secretaria da Delegação Brasileira no Parlamento do MERCOSUL Montevidéu: Departamento de Documentación y Normativa-Secretaria Parlamentaria, 2007. Disponível em: <http:// www.parlamentodelmercosur.org/innovaportal/v/4296/1/ secretaria/\%20Documentos_de_refer\%C $3 \%$ A Ancia. html? seccion=2>. Acesso em: 15 jul. 2013.

PARLASUL suspende atividades por falta de dinheiro. Revista 
Época, São Paulo, maio 2015. Disponível em: <http://epoca.globo. com/tempo/expresso/noticia/2015/05/parlasul-suspendeatividades-por-falta-de-dinheiro.html $\geq$, Acesso em: 6 jun. 2015.

PIETRAFESA, P. A. A construção de uma nova instituição parlamentar no Cone Sul: o Parlamento do MERCOSUL. 2009. Dissertação (Mestrado em Estudos Comparados) - Centro de Pesquisa e Pós-Graduação sobre as Américas, Instituto de Ciências Sociais, Universidade de Brasília, Brasília, 2009.

SANTOS, L. C. V. G. dos. A América do sul no discurso diplomático brasileiro. Brasília: FUNAG, 2014.

SANTOS, L. C. V. G. dos. A América do Sul no discurso diplomático brasileiro. Revista Brasileira de Política Internacional, Brasília, v. 48, n. 2, p. 185-204, jul./dez. 2005.

TAJRA, J. L. F. Integração Sul-Americana: uma incursão ao conceito de cidadania no âmbito do Parlamento do MERCOSUL. 2014. Dissertação (Mestrado Acadêmico em Políticas Públicas e Sociedade) - Centro de Estudos Sociais Aplicados, Universidade Estadual do Ceará, dissertação de mestrado, Fortaleza, 2014a.

A representação cidadã no MERCOSUL e a cidadania sulamericana: o Parlamento do MERCOSUL como instrumento de fortalecimento da integração. In: CONGRESO NACIONAL, 11.; CONGRESO INTERNACIONAL SOBRE DEMOCRACIA, 4., 8 a 11 set. 2014, Rosário, Argentina. Anales... Rosário, Argentina: Faculdade de Ciência Política e Relações Internacionais; Universidade Nacional de Rosário, 2014b.

TAJRA, J. L. F.; MARTINS, M. D. O Parlamento do MERCOSUL e a cidadania sul-americana. Revista Eletrônica de Ciência Política, v. 5, n. 2, 2014c. Disponível em: <http://ojs.c3sl.ufpr.br/ ojs2/index.php/politica/article/view/35733/25378>. Acesso em: 31 out. 2015. 